\title{
The Underperformance of Acquiring Mutual Funds: A Re-Examination of a Puzzle
}

\author{
Manel Kammoun ${ }^{1} \&$ Djerry C. Tandja M. ${ }^{1}$ \\ ${ }^{1}$ Département des sciences administratives, Université du Québec en Outaouais, Saint-Jérôme, Canada \\ Correspondence: Manel Kammoun, Département des Sciences Administratives, Université du Québec en \\ Outaouais, Saint-Jérôme, Québec, J7Z 0B7, Canada. Tel: 1-450-530-7616, ext. 1751. E-mail: \\ manel.kammoun@uqo.ca
}

Received: April 30, 2021

doi:10.5539/ijef.v13n7p77

\begin{abstract}
This paper studies the performance of Canadian acquiring mutual funds in the post-acquisition period by using 339 acquisitions during the period of 2008-2015. Contrary to the facts reported in studies in the U.S., we find that, for within-family mergers, the performance and the size of acquiring funds increase after the merger. Overall, our results suggest that the within-family merger of Canadian mutual funds is a win-win scenario for participating funds, as acquiring and target funds' performance increases after the merger. Our results are consistent with a model where board of directors of merging funds are able to select value-enhancing acquisition opportunities, as they hold, due to the management structure of Canadian mutual funds, superior information about within-family target funds.
\end{abstract}

Keywords: Canadian equity funds, mergers, performance evaluation

\section{Introduction}

In recent years, the determinants of mutual funds mergers and their impact on the performance and size of participating funds have received considerable attention in finance literature (Note 1). As a result, it is shown that, unlike target funds, acquiring funds experience performance deterioration after the merger. Recent literature finds mitigate results on post-merger performance for the two merger parties. Lappatto and Puttonen (2018) find that target funds would have outperformed the acquiring funds after the merger if they continued as a buy-and-hold strategy based on its final holdings prior to the merger. Recently, Alda et al. (2020) analyse the consequences of mergers for socially responsible acquiring funds and show that, after the merger, acquiring funds benefit from better performance and are more efficient. Zalewska and Zhang (2020) examine mergers that occurred in the years following the financial crisis and show that both the acquirers and the targets suffer from worse post-merger performance. Empirical evidence on the impact of mergers on acquiring fund size is also mixed. While Jayaraman et al. (2002) find that funds participating in mergers tend to be shrinking in size, Andreu and Sarto (2016) and McLemore (2019) show that the size of acquiring funds increases after the merger. In general, existing literature suggests that mutual funds' mergers benefit more to target funds.

However, these studies focused on Capital markets (e.g. U.S.) where each mutual funds have its own boards of directors. In the U.S. and most countries, except in Canada, the Investment Company Act requires mutual funds to have their own boards of directors (Note 2). Considering that merger decision is made by the board of directors of the merging funds, we argue that this may explain the negative post-acquisition performance of acquiring funds in such markets (Note 3). Indeed, the board of directors might not have superior information about target funds although they have access to some level of information. Thus, board of directors might not be able to select value-enhancing acquisition opportunities. In Canada, board of directors occur at the family and not fund level (Alpert et al., 2013, p. 13). Thus, board of directors of Canadian funds benefit from holding superior information about Canadian target funds belonging to the same family which might help in selecting value-enhancing acquisition opportunities. In fact, Kacperczyk et al. (2005) show that managers who concentrate their investments in industries on which they hold information achieve better performance. Nain and Yao (2013) show that the success of mergers is partly driven by stock selection ability of fund manager. Kaprielyan et al. (2020) argue that mutual fund managers who perform active trading on merger announcement achieve a better risk-adjusted fund returns, resulting from their stock picking ability. We argue that management structure of 
mutual funds may affect the target selection process and therefore the post-acquisition performance and size of acquiring funds, especially for within-family mergers. Consequently, in this study we analyze the post-acquisition performance of Canadian acquiring funds subject to a different management structure.

Using a sample of 339 Canadian mutual fund acquisitions during the period of 2005-2015, for the full sample and the within-family mergers, we find that both acquiring and target fund shareholders appear to be winners of the acquisition, as their funds' performance increase after the merger. We attribute the significant improvements in performance of acquiring funds to the fund manager's ability to select value-enhancing acquisition opportunities because they have superior information about both funds from being part of the board of director for both. In addition, we find that the size of acquiring funds increases, especially for within-family mergers. The increase in funds size is attributed to the attractiveness of the funds due to the superior performance display after the merger (Jayaraman et al., 2002). Like in most countries, except the U.S., Canadian mutual funds suffer from high levels of fees and expenses. Ruckman (2003) showed that expenses paid by Canadian mutual fund investors is 50\% higher than that paid in the U.S. He claims that Canadian funds do not benefit from economies of scale due to the much smaller size of assets under management. This paper presents evidence on improved performance and size of Canadian acquiring and target funds' which are subject to different management structures than those in the U.S and most countries.

The remainder of this paper is organized as follows: section 2 describes the mutual fund data; section 3 presents fund characteristics and interprets our empirical results on pre-merger and post-merger performance; Finally, section 4 concludes.

\section{Data and Descriptive Statistics}

Our data on Canadian domestic open-ended equity mutual funds come from Morningstar Direct. A set of rules were followed to form our sample: first, for each merger, a target fund and an acquiring fund are identified, along with the merger date (Note 4); second, we exclude mergers missing the acquiring fund identifier or their historical data; third, following Jayaraman et al. (2002), Khorana et al. (2007), and Namvar and Phillips (2013), we exclude target and acquiring mutual funds that do not have a complete return history over the three years before and after the month of the merger. As shown in Figure 1, the first merger happened in 2008. Following our rules, the study period selected covers the period 2005-2018 to allow for the risk-adjusted performance estimation of the funds in the three years before and after the merger date. Mergers after 2015 are excluded because the database ended in 2018. Considering all previous filters, the sample includes 339 open-ended Canadian equity mutual fund mergers, 246 acquiring funds, and an average of 1.38 acquisitions per acquirer between 2008 and 2015. We then divided our sample into two groups: 117 across-family mergers and 222 within-family mergers. We consider a merger as a within-family merger if acquiring and target funds have the same "management company code"; otherwise, it is considered an across-family merger.

The database contains monthly returns, total net assets (TNA), expense ratio, turnover ratio, and inception date. Fund age is the difference in months between the current date and the date the fund was first offered. Fund flow is calculated following Sirri and Tufano (1998):

$$
\text { Flow }_{M F, t}=\frac{\left[T N A_{M F, t}-T N A_{M F, t-1} R_{M F, t}\right]}{T N A_{M F, t-1}}
$$

where $T N A_{M F, t}$ is the total net assets of the fund (MF) in year t and t-1 and $R_{M F, t}$ is the fund return in year t.

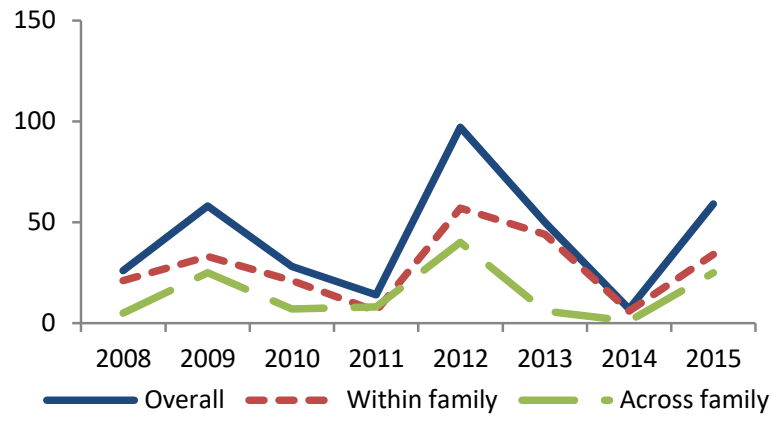

Figure 1. Number of fund merger deals

Note. Figure 1 displays the number of fund mergers in each year of the overall mergers (Full Sample), within-family mergers (Within-family), and across-family mergers (Across-family) over the period 2008-2015. 
Figure 1 displays the number of mergers in each year of the overall mergers (Full Sample), mergers within the same fund family (within-family), and mergers between funds from different fund families (Across-family) from 2008 to 2015. We note approximately two merger waves corresponding to 2008-2010 and 2011-2014. Consistent with prior analysis on the U.S. mutual fund industry, the majority of mergers occur within the same fund family (Note 5): $65.5 \%$ of mergers are classified as within-family mergers and $34.5 \%$ as across-family mergers.

Table 1 presents the summary statistics for the average fund characteristics of the mutual fund sample and distinguishes between the targets and the acquiring funds. The acquiring funds seem to be larger and older and to have higher average returns and lower expenses than their targets. This evidence is consistent with prior literature (Jayaraman et al., 2002; Ding, 2006; and Karoui \& Kooli, 2014). Unlike the U.S, Canadian target funds experience higher turnover and attract more flows than their acquiring counterparts.

Table 1. Summary statistics for the average fund characteristics

\begin{tabular}{ccccc}
\hline & Mean & StdDev & Min & Max \\
\hline & & Panel A: Acquirer's Characteristics & & 2729.232 \\
Size (\$ Million) & 120.627 & 331.837 & 0.001 & 2.439 \\
Returns (\%) & 0.291 & 0.452 & -1.616 & 0.047 \\
Expense Ratio (\%) & 0.021 & 0.007 & 0.001 & 5.034 \\
Turnover & 0.748 & 0.649 & 0.004 & 610.512 \\
Age (Months) & 81.387 & 94.307 & -14.701 & 25.702 \\
Flows & 2.598 & 2.380 & 1.948 & 745.865 \\
Size (\$ Million) & 29.857 & Panel B: Target's Characteristics & 0.001 & 1.653 \\
Returns (\%) & 81.851 & -1.588 & 0.099 \\
Expense Ratio (\%) & 0.113 & 0.473 & 0.001 & 30.297 \\
Turnover & 0.022 & 0.009 & 0.004 & 607.773 \\
Age (Months) & 0.951 & 2.270 & 18.485 & 1.882 \\
Flows & 65.426 & 61.202 & 148.240 \\
\hline
\end{tabular}

Note. This table presents summary statistics (average (Mean), standard deviation (StdDev), minimum (Min) and maximum (Max)) for acquirer's (panel A) and target's characteristics (panel B). Fund's characteristics include the total net assets (TNA), the monthly returns (Returns), the annual expense ratio (Expenses), the minimum of aggregated sales or aggregated purchases of securities divided by the average twelve-month TNA of the fund (Turnover), the difference in months between the current date and the date the fund was first offered (Age), the fund flows (Flows).

\section{Fund Performance and Characteristics Surrounding Mergers}

In this section, we examine the pre-merger performance of targets and the pre-merger and post-merger performance of acquiring funds. We estimate the risk-adjusted performance of funds using the Carhart (1994) 4-factor model alpha (Note 6):

$$
R_{i, t}-R_{f, t}=\alpha_{i t}+\beta_{1, i} M K T_{t}+\beta_{2, i} S M B_{t}+\beta_{3, i} H M L_{t}+\beta_{4, i} M O M_{t}+\varepsilon_{i, t}
$$

where $R_{i, t}$ are the fund returns in month $\mathrm{t}$ and $R_{f, t}$ is the 1-month Treasury bill rate in month t. $M K T_{t}$ is the market return at $\mathrm{t}$ net of the 1-month T-bill rate. $S M B_{t}$ is the difference between the return of portfolios constituted of small firms and portfolios constituted of big firms; $H M L_{t}$ is the difference in return between portfolios formed according to high and low BE/ME ratios, and $M O M_{t}$ is the difference between the return of portfolios constituted of high past returns and portfolios constituted of low past returns. $\beta_{1, i}, \beta_{2, i}, \beta_{3, i}$ and $\beta_{4, i}$ are the associated sensitivities.

Following L'Her et al. (2001), Bauer, Derwall and Otten (2007), Ayadi et al. (2016) and others, we construct the monthly Canadian four factors, especially the Fama and French factors (Fama and French, 1993) and the Carhart momentum factor (Carhart, 1997). The sample contains all Canadian firms on Compustat and our starting date corresponds to four years before the date of the first merger, from 2004 to 2018 (Note 7). Firms with negative or missing book equity (BE) or missing market equity (ME) are eliminated. Considering all previous steps, we have a final sample of 2039 stocks between 2004 and 2018.

The size factor (SMB), the book-to-market factor (HML), and the momentum factor (MOM) are constructed as on Kenneth French's website. The market portfolio is the monthly capitalization-weighted return of all the securities considered. The risk-free rate is the monthly 1-month Canadian Treasury Bills taken from the Bank of Canada website. 
Table 2 presents summary statistics on the distribution of the four factors: market excess returns, SMB, HML, and MOM, for the Canadian stock market (Panel A) as well as the U.S. stock market (Panel B), which will serve as a basis for comparison.

Table 2. Summary statistics - Four factors returns

\begin{tabular}{lllll}
\hline & RM & SMB & HML & MOM \\
\hline Canada & & & & \\
\hline Mean & 1.107 & 1.210 & -0.553 & 0.164 \\
StdDev & 3.887 & 4.329 & 2.782 & 0.577 \\
Min & -16.142 & -13.617 & -11.314 & -1.604 \\
Max & 13.523 & 15.351 & 8.228 & 3.316 \\
\hline U.S. & & & & 0.133 \\
Mean & 0.614 & 0.049 & -0.070 & 4.423 \\
StdDev & 4.114 & 2.305 & 2.542 & -34.390 \\
Min & -17.230 & -4.760 & -11.180 & 12.530 \\
Max & 11.350 & 6.100 & 8.290 & \\
\hline
\end{tabular}

Note. This table presents summary statistics for four factors monthly returns on the 2005-2018 period for both Canadian and U.S. stock returns. RM stands for the excess return of the market portfolio obtained from the firms considered in the sample over the 1-month T-bill rate. $\mathrm{SMB}$ is the difference between the return of portfolios constituted of small firms and portfolios constituted of big firms; HML is the difference in return between portfolios formed according to high and low BE/ME ratios, and MOM is the difference between the return of portfolios constituted of high past returns and portfolios constituted of low past returns. Descriptive statistics include mean, standard deviation (StdDev), minimum (Min), maximum (Max), and percentiles. All statistics are in percentages.

The average monthly returns on SMB and HML are respectively equal to $1.21 \%$ and $-0.553 \%$, with standard deviations of $4.329 \%$ and $2.782 \%$ for the Canadian stock market. The SMB premium is larger and more volatile than the one observed in the U.S. However, the HML premium is lower and as volatile as the premium found in the U.S. The MOM factor average is comparable to the one observed in the U.S. over the 2005-2018 period; however, it is less volatile. Finally, the Canadian market premium is higher and less volatile than the premium found in the U.S.

Following Jayaraman et al. (2002), Khorana et al. (2007) and Namvar and Phillips (2013), we estimate the model using 24 observations over four timeframes: -36 to $-13,-24$ to -1 and 1 to 24 and 13 to 36 . We refer to these intervals as P2, P1, A1, and A2, respectively. We exclude the month of the merger from the performance analysis.

\subsection{Performance Differences for Acquiring and Target Funds}

Table 3 displays the mean difference tests between acquiring funds and their respective targets' performances for the six years surrounding the merger, using 24 observations over two timeframes: -36 to $-13,-24$ to -1 , and 1 to 24 and 13 to 36 . We refer to these intervals as P2, P1, A1, and A2, respectively. As table 3 shows, acquiring funds perform better than target funds in the pre-merger period. Focussing on the full sample, results show that the mean differences in alphas are equal to $0.707 \%$ for the interval P2 and $0.532 \%$ for the interval P1. The difference values are statistically significant for the full sample, across- and within-family mergers. For across-family (within-family) mergers, the mean differences in alphas are equal to $0.591 \%(0.769 \%)$ for the interval P2 and $0.614 \%(0.488 \%)$ for the interval P1. These findings suggest that Canadian mutual fund mergers are mainly motivated by the target funds' poor performance. Table 3 suggests also that target funds realize significant benefits in term of improved performance after mergers, a finding in line with Jayaraman et al. (2002).

Unlike Jayaraman et al. (2002), Allen and Parwada (2006), and Andreu and Sarto (2016), the analysis of the mean difference tests in the post-merger period (for the full sample and the within-family mergers) suggests that the performance of acquiring funds increases, being the mean difference statistically significant. We argue that, compared to the U.S., the management structure of the Canadian mutual fund industry generates better post-acquisition performance of acquiring funds. When considering across-family mergers, we find no evidence of the better performance of acquiring funds in the post-merger period, being the mean difference not statistically significant. The results confirm the findings of Nain and Yao (2013) that funds with higher stock selection skills make more successful acquisitions. In line with Namvar and Philipps (2013), we find that post-merger performance is related to compatibility in management objectives between funds. Hence, within-family mergers 
between funds with similar investment strategies (as they have the same board of directors) outperform across-family mergers with dissimilar management objectives. Overall, the better post-acquisition performance of within the family mergers leads to an improved full sample performance.

Table 3. Performance differences between target and acquiring funds

\begin{tabular}{llll}
\hline & Full Sample & Across-family mergers & Within-family mergers \\
\hline$\alpha_{P_{2}}^{A}-\alpha_{P_{2}}^{T}$ & 0.3220 & 0.4334 & 0.2632 \\
& $(<.0001)$ & $(<.0001)$ & $(<.0001)$ \\
$\alpha_{P_{1}}^{A}-\alpha_{P_{1}}^{T}$ & 0.3110 & 0.4048 & 0.2616 \\
& $(<.0001)$ & $(<.0001)$ & $(<.0001)$ \\
$\alpha_{A_{2}}^{A}-\alpha_{P_{2}}^{A}$ & 0.386 & 0.2499 & 0.5060 \\
& $(<.0001)$ & $(0.1842)$ & $(<.0001)$ \\
$\alpha_{A_{1}}^{A}-\alpha_{P_{1}}^{A}$ & 0.221 & 0.210 & 0.2260 \\
& $(<.0001)$ & $(0.2500)$ & $(<.0001)$ \\
$\alpha_{A_{2}}^{A}-\alpha_{P_{2}}^{T}$ & 0.7077 & 0.5909 & 0.7693 \\
& $(<.0001)$ & $(<.0001)$ & $(<.0001)$ \\
$\alpha_{A_{1}}^{A}-\alpha_{P_{1}}^{T}$ & 0.5316 & 0.6147 & 0.4879 \\
& $(<.0001)$ & $(<.0001)$ & $(<.0001)$ \\
\hline
\end{tabular}

Note. Table 3 reports the mean difference test of fund performance $(\alpha)$ between acquiring (A) and target (T) funds for the six-year period surrounding the merger, and their p-values (values between brackets), using 24 observations over two timeframes: -36 to $-13,-24$ to -1 and 1 to 24 and 13 to 36 . We refer to these intervals as P2, P1, A1, and A2, respectively. The data cover the period January 2005-December 2018. All statistics are in percentage except the p-values.

\subsection{Fund Characteristics Surrounding Mergers}

In this section, we carry out an analysis of the acquirer's and the target's characteristics surrounding the merger, and we distinguish between across- and within-family mergers. Table 4 shows the mean difference tests of the acquirer's and the target's characteristics surrounding the merger. Fund characteristics include size, expenses, turnover, and flows for acquiring and target funds over the six years around the merger.

Regarding fund size, the results show that in the pre-merger period, acquiring funds are larger than target funds, suggesting that small funds are more likely to be acquired. This difference increases as the merger date is approaching. This result is significant at the 1\% confidence level. As suggested by Andreu and Sarto (2016), two motives may impel firms to acquire small funds. First, the poor performance of a small fund makes it hard to grow. Second, a small fund acquisition would leave less impact on the fund family compared to a large fund merging. After the merger, the size of acquiring funds increases (Andreu \& Sarto, 2016), especially for the full sample and the within-family mergers, which would be attributable to the acquisition of the target funds' assets. However, for the across-family mergers, our findings are consistent with Jayaraman et al. (2002) as funds participating in mergers tend to be shrinking in size. Table 4 shows that the acquiring fund's size does not increase for across-family mergers. This result is not surprising, since the across-family mergers do not provide superior performance to attract additional assets.

In line with McLemore (2019), we find that acquiring funds benefit from lower expenses in the three years following the merger. We argue that the acquiring funds benefit from lower expenses for three reasons: (1) the increase in size may result in scale of economies, as Canadian mutual fund industry suffers from having the highest fees and expenses internationally due to the small size of assets under management at both family and fund level (Ruckman, 2003); (2) the Canadian distribution model uses mainly no-load funds (Alpert et al., 2011). This absence of commission or sales charge allows funds to control the increase of their expenses due to advertisement of the newly merged fund as documented by Barber et al. (2005); and (3) unlike the U.S., the lower competition in Canadian mutual fund industry may discourage managers of acquiring funds to make big investments in advertising the newly merged fund.

Table 4 shows also that the decrease in turnover of acquiring funds is statistically significant for all mergers and for across-family mergers, which is consistent with the findings of McLemore (2019). However, the increase in turnover is not significant for within-family mergers, suggesting that mergers do not have an effect on turnover. Unlike Jayaraman et al. (2002) and Karoui and Kooli (2014), the mean asset flows are higher for target funds 
than for acquiring funds prior to the merger. However, acquiring funds succeed to attract additional assets in the two years following the merger, especially for full sample and within-family mergers. This result is not surprising, since acquiring funds realize significant improvements in performance after the merger, except for across-family mergers.

Table 4. Characteristics of acquiring and target funds around mutual fund mergers

\begin{tabular}{|c|c|c|c|c|c|c|}
\hline & \multicolumn{2}{|l|}{ Full sample } & \multicolumn{2}{|c|}{ Across-family } & \multicolumn{2}{|c|}{ Within-family } \\
\hline & Mean diff & p-value & Mean diff & p-value & Mean diff & p-value \\
\hline$T N A_{P_{2}}^{A}-T N A_{P_{2}}^{T}$ & 93,1542 & $<.0001$ & 60,3532 & $<.0001$ & 110,0769 & $<.0001$ \\
\hline$T N A_{P_{1}}^{A}-T N A_{P_{1}}^{T}$ & 100,9015 & $<.0001$ & 60,9474 & $<.0001$ & 120,2852 & $<.0001$ \\
\hline$T N A_{A_{2}}^{A}-T N A_{P_{2}}^{A}$ & 4,7665 & $<.0001$ & $-1,2741$ & 0.1127 & 7,9306 & $<.0001$ \\
\hline$T N A_{A_{1}}^{A}-T N A_{P_{1}}^{A}$ & 9,1037 & $<.0001$ & 0,4223 & 0.3072 & 13,3584 & $<.0001$ \\
\hline $\exp _{P_{2}}^{A}-\exp _{P_{2}}^{T}$ & $-0,1209$ & $<.0001$ & $-0,1141$ & $<.0001$ & $-0,1250$ & $<.0001$ \\
\hline $\exp _{P_{1}}^{A}-\exp _{P_{1}}^{T}$ & $-0,1870$ & $<.0001$ & $-0,2800$ & $<.0001$ & $-0,1337$ & $<.0001$ \\
\hline $\exp _{A_{2}}^{A}-\exp _{P_{2}}^{A}$ & $-0,0470$ & $<.0001$ & $-0,0752$ & 0.0003 & $-0,0311$ & 0.0003 \\
\hline $\exp _{A_{1}}^{A}-\exp _{P_{1}}^{A}$ & $-0,0337$ & $<.0001$ & $-0,0550$ & $<.0001$ & $-0,0220$ & 0.0067 \\
\hline $\operatorname{turn} n_{P_{2}}^{A}-\operatorname{turn}_{P_{2}}^{T}$ & $-6,1992$ & 0.0184 & $-8,1445$ & 0.0110 & $-5,0777$ & 0.4673 \\
\hline $\operatorname{turn}_{P_{1}}^{A}-\operatorname{turn}_{P_{1}}^{T}$ & $-9,2687$ & 0.6975 & $-10,6508$ & 0.1659 & $-8,4605$ & 0.0250 \\
\hline $\operatorname{turn}_{A_{2}}^{A}-\operatorname{turn}_{P}^{A}$ & $-19,4751$ & $<.0001$ & $-56,2608$ & $<.0001$ & 0,5094 & 0.5501 \\
\hline $\operatorname{turn}_{A_{1}}^{A}-\operatorname{turn}_{P_{1}}^{A}$ & $-8,5577$ & 0.0001 & $-27,6930$ & $<.0001$ & 2,1034 & 0.7037 \\
\hline flows $P_{P_{2}}^{A}-$ flows $s_{P_{2}}^{T}$ & $-1,3223$ & 0.0010 & $-0,0690$ & 0.4560 & $-1,9760$ & 0.0003 \\
\hline flows $_{P_{1}}^{A}-$ flows $_{P_{1}}^{T}$ & $-0,7195$ & $<.0001$ & $-0,1355$ & 0.0047 & $-1,0086$ & $<.0001$ \\
\hline flows $_{A_{2}}^{A}-$ flows $_{P_{2}}^{A}$ & 0,2432 & 0.5205 & 0,1796 & 0.8122 & 0,3280 & 0.2409 \\
\hline flows ${ }_{A_{1}}^{A}-$ flows $s_{P_{1}}^{A}$ & 0,4538 & 0.0308 & 0,4464 & 0.3447 & 0,3452 & 0.0429 \\
\hline
\end{tabular}

Note. Table 4 presents the mean difference test (Mean diff) and their p-values between the acquirer (A) and the target (T) for the total net assets in \$ Million (TNA),the expenses in percentage (exp), the turnover in percentage (turn) and fund flows (flows) for the six years surrounding the merger: -36 to $-13,-24$ to -1 and 1 to 24 and 13 to 36 . We refer to these intervals as P2, P1, A1, and A2, respectively. This table reports the results for the full sample, the across-family mergers, and the within-family mergers.

\section{Conclusion}

This paper examines the performance of Canadian acquiring mutual funds in the post- acquisition period. Our empirical results show that, contrary to several empirical papers, in Canadian mutual fund industry, the performance of acquiring funds (for within family mergers and full sample) increases after the merger. Moreover, our study shows that the size of acquiring funds increases after the merger. Overall, this paper makes a valuable contribution to the pool of knowledge by being the first comprehensive study of mutual fund mergers to show that: In a different management structure, mergers could be a win-win situation for participating funds. Results provide practical implications for Canadian fund managers, policymakers and researchers. Indeed, they show that Canadian fund managers interested in Mergers and Acquisitions will benefit from within-fund family mergers, as they will benefit from holding superior information and select value-enhancing acquisition opportunities. They provide also new understanding to policymakers, practitioners and researchers on the effects of fund management structure on post-merger performance. Future work could examine the motivation for Canadian across-family mergers despite the negative implications for performance.

\section{Acknowledgments}

Manel Kammoun thanks the Social Sciences and Humanities Research Council of Cananda (SSHRC grant number 430-2017-00663) for financial support.

\section{References}

Alda, M., Muñoz, F., \& Vargas, M. (2020). Socially responsible mutual fund exit decisions. Business Ethics: A European Review, 29(1), 82-97. https://doi.org/10.1111/beer.12253

Allen, D., \& Parwada, J. T. (2006). Investors' response to mutual fund company mergers. International Journal 
of Managerial Finance, 2(2), 121-135. https://doi.org/10.1108/17439130610657340

Alpert, B., Rekenthaler, J., \& Suh, S. (2013). Global fund investor experience. Morningstar research papers. Retrieved from http://www.investingforme.com/pdfs/reports-studies/Global-Fund-Investor-Experience-Report-2013.pdf

Andreu, L., \& Sarto, J. L. (2016). Financial consequences of mutual fund mergers. European Journal of Finance, 22(7), 529-550. https://doi.org/10.1080/1351847X.2013.858055

Ayadi, M., Chaibi, A., \& Kryzanowski, L. (2016). Performance of Canadian hybrid mutual funds. North American Journal of Economics and Finance, 38, 124-147. https://doi.org/10.1016/j.najef.2016.09.003

Bauer, R., Derwall, J., \& Otten, R. (2007). The Ethical Mutual Fund Performance Debate: New Evidence from Canada. Journal of Business Ethics, 70, 111-124. https://doi.org/10.1007/s10551-006-9099-0

Carhart, M. M. (1997). On persistence in mutual fund performance. Journal of Finance, 52, 57-82. https://doi.org/10.1111/j.1540-6261.1997.tb03808.x

Ding, B. (2006). Mutual fund mergers: A long-term analysis. Working paper. http://dx.doi.org/10.2139/ssrn.912927

English, P. C., Demiralp, I., \& Dukes, W. P. (2011). Mutual fund exit and mutual fund fees. Journal of Law and Economics, 549(3), 723-749. https://doi.org/10.1086/658492

Fama, E. F., \& French, K. R. (1993). Common risk factors in the returns on stocks and bonds. Journal of Financial Economics, 33, 3-56. https://doi.org/10.1016/0304-405X(93)90023-5

Jayaraman, N., Khorana, A., \& Nelling, E. (2002). An analysis of the determinants and shareholder wealth effects of mutual fund mergers. Journal of Finance, 57, 1215-1542. https://doi.org/10.1111/1540-6261.00468

Kacperczyk, M., Sialm, C., \& Zheng, L. (2005). On the industry concentration of actively managed equity mutual funds. Journal of Finance, 60, 1983-2011. https://doi.org/10.1111/j.1540-6261.2005.00785.x

Kaprielyan, M., Hossain, M. M., \& Danso, C. A. (2020). Mutual fund trading around mergers and fund performance. International Journal of Managerial Finance, 16(1), 1-20. https://doi.org/10.1108/IJMF-07-2017-0134

Karoui, A., \& Kooli, M. (2014). Diversification versus concentration motives in mutual fund mergers. Journal of Wealth Management, 17(2), 9-18. https://doi.org/10.3905/jwm.2014.17.2.009

Khorana, A., Tufano, P., \& Wedge, L. (2007). Board structure, mergers and shareholder wealth: A study of the mutual fund industry. Journal of Financial Economics, 85, 571-598. https://doi.org/10.1016/j.jfineco.2006.05.002

L'Her, J. F., Masmoudi, T., \& Suret, J. M. (2004). Evidence to support the four-factor pricing model from the Canadian stock market. Journal of International Financial Markets, Institutions and Money, 14(4), 313-328. https://doi.org/10.1016/j.intfin.2003.09.001

Lai, C. (2016). Independent directors and favoritism: When multiple board affiliations prevail in mutual fund families. Financial Management, 45(3), 529-582. https://doi.org/10.1111/fima.12131

Lapatto, A., \& Puttonen, V. (2018). Life after death: acquired fund performance. Managerial Finance, 44(3), 389-402. https://doi.org/10.1108/MF-02-2017-0031

McLemore, P. (2019). Do mutual funds have decreasing returns to scale? Evidence from fund mergers. Journal of Financial and Quantitative Analysis, 54(4), 1683-1711. https://doi.org/10.1017/S0022109018001023

Nain, A., \& Yao, T. (2013). Mutual fund skill and the performance of corporate acquirers. Journal of Financial Economics, 110, 437-456. https://doi.org/10.1016/j.jfineco.2013.06.005

Namvar, E., \& Phillips, B. (2013). Commonalities in investment strategy and the determinants of performance in mutual fund mergers. Journal of Banking and Finance, 37, 625-635. https://doi.org/10.1016/j.jbankfin.2012.10.001

Park, M. (2013). Understanding merger incentives and outcomes in the U.S. mutual fund industry. Journal of Banking and Finance, 37(11), 4368-4380. https://doi.org/10.1016/j.jbankfin.2013.07.048

Ruckman, K. (2003). Expense ratios of north american mutual funds. Canadian Journal of Economics, 36(1), 192-223. https://doi.org/10.1111/1540-5982.00010 
Sirri, E., \& Tufano, P. (1998). Costly search and mutual fund flows. Journal of Finance, 53, 1589-1622. https://doi.org/10.1111/0022-1082.00066

Zalewska, A. A., \& Zhang, Y. (2020). Mutual funds' exits, financial crisis and Darwin. Journal of Corporate Finance, 65, 1-26. https://doi.org/10.1016/j.jcorpfin.2020.101738

Zhao, X. (2005). Exit decision in the U.S. mutual fund industry. The Journal of Business, 78(4), 1365-1401. https://doi.org/10.1086/430863

\section{Notes}

Note 1. using both U.S. mutual funds (Jayaraman et al., 2002; Zhao, 2005; Ding, 2006; Khorana et al., 2007; English et al., 2011; Namvar \& Phillips, 2013; Park, 2013; Karoui \& Kooli, 2014; Lai, 2016; and McLemore, 2019 ) and international mutual funds (Allen \& Parwada, 2006; and Andreu \& Sarto, 2016).

Note 2. See 15 U.S.C. § 80a-10(a) (2006).

Note 3. See the Appendix of Jayaraman et al. (2002) for details on mutual funds mergers.

Note 4. Specifically, we identify mergers using three variables: (1) obsolete type code: "Merged"; (2) obsolete date, which specifies the merger date; and (3) Merged into security, which identifies the acquiring fund.

Note 5. See, for example, Khorana et al. (2007) and Namvar and Phillips (2013).

Note 6. To measure fun performance, we also use the Fama and French (1993) three factor alpha and find similar results.

Note 7. We identify Canadian firms by Stock exchange codes: 0, 1, 7, 8, 9 and 10; Security monthly descriptor code C; and State codes AB, BC, PE, MB, NB, NS, ON, QC, SK, NL, NU, NT and YT.

\section{Copyrights}

Copyright for this article is retained by the author(s), with first publication rights granted to the journal.

This is an open-access article distributed under the terms and conditions of the Creative Commons Attribution license (http://creativecommons.org/licenses/by/4.0/). 